\title{
MULTICULTURALISMO: OLHARES NECESSÁRIOS AOS TERRITÓRIOS E PROBLEMATIZAÇÕES DA CONSTRUÇÃO DA BASE NACIONAL COMUM
}

\author{
MAURÍCIO, Wanderléa Pereira Damásio ${ }^{1}$ \\ ANDRADE, Izabel Cristina Feijó de ${ }^{2}$
}

\begin{abstract}
RESUMO:
O artigo "Multiculturalismo: olhares necessários aos territórios e problematizações da construção da Base Nacional Comum" apresenta uma discussão sobre o contexto de um currículo multicultural, bem como explora conceitos relacionados a problemática: quais os indicativos de um currículo multicultural que estão presentes nas Diretrizes Curriculares Nacionais (2013) e que nos impulsionam para uma perspectiva de Base Nacional Comum que vigore a respeito da pluralidade de valores e culturas no âmbito educacional. Autores como MOREIRA (2010), (MOREIRA \& CANDAU, 2008), ANPED (2015), Apple (2006), Diretrizes Curriculares Nacionais e a Base Nacional Comum alicerçaram os estudos desse artigo. O objetivo desse estudo foi discutir o significado de um currículo multicultural presente nas Diretrizes Curriculares Nacionais e explicitado na Base Nacional Comum. Para alcançar o objetivo proposto, a metodologia adotada compreendeu análise documental das Diretrizes Curriculares Nacionais (BRASIL, 2013) e suas indicações para um currículo multicultural. A técnica da pesquisa foi a análise de conteúdo. Resultados preliminares apontam que os indicativos de um currículo multicultural presentes nas Diretrizes Curriculares Nacionais (2013) e que nos impulsionam para uma perspectiva de Base Nacional Comum precisa conceber o contexto da sala de aula, as implicações em seu entorno e amplo debate de conhecimentos que compreendam e atue sobre a "realidade Cultural Contemporânea" (MOREIRA, 2010 p. 176) para que vigore o respeito e a pluralidade de valores e culturas no âmbito educacional.
\end{abstract}

Palavras-chave: Multiculturalismo. Base Nacional Comum. DiretrizesCurricularesNacionais.

\section{ABSTRACT}

The article presents a discussion about a multicultural curriculum and explores concepts related: which basis of a multicultural curriculum has been presented in the National Curriculum Guidelines (2013) that point to a Common National Basis in order to enforce the respect upon of values and cultures in the educational field. The studies of this article has underpinned by Authors like MOREIRA (2010) (MOREIRA \& CANDAU, 2008), ANPED (2015), Apple (2006), also by the National Curriculum

${ }^{1}$ Doutora em Educação pela PUCRS. Professora do Centro Municipal de SJ/SC. Email: andrade@technologist.com

${ }^{2}$ Doutora em Educação pela UNISINOS. Professora do Centro Municipal de SJ/SC. Email: andrade@technologist.com 


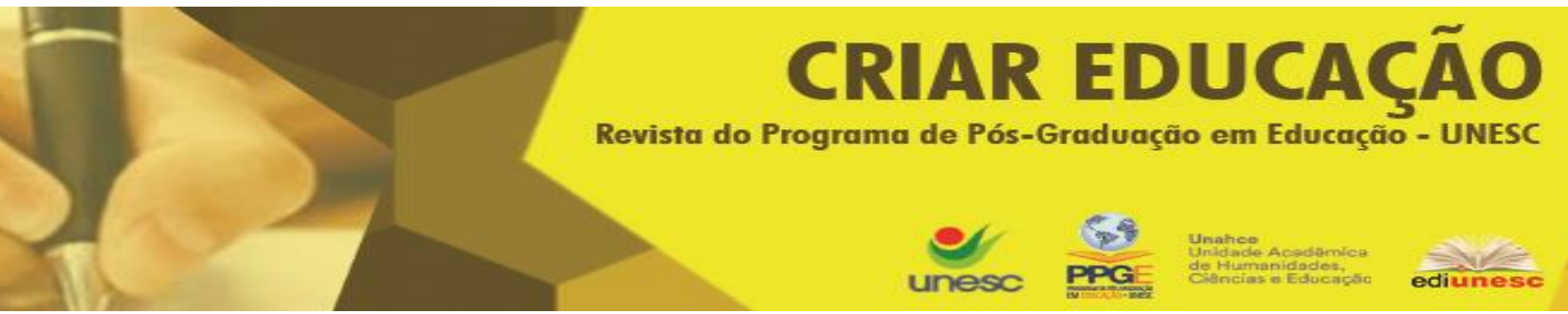

Guidelines and Common National Base. The purpose of this study was to discuss the meaning of multicultural curriculum in the National Curriculum Guidelines and presented in the Common National Base. To achieve the proposed goal, the adopted methodology included documentary analysis of the National Curriculum Guidelines (BRAZIL, 2013) and its indications in order to adopt a multicultural curriculum. The technical of research applied was analysis of content. Preliminary results show that the indicatives of multicultural curriculum present in Guidelines National Curriculum (2013) drive us to a perspective of Common National Base, they need to consideer the classroom context, the implications in their surroundings and broad discussion of knowledge understand and act on the "Cultural Contemporary reality" (MOREIRA, 2010 p. 176) in order to operate respect and plurality of values and cultures in the educational field.

KEY WORDS: Multiculturalism. National Common Base. National Curriculum Guidelines.

\section{INTRODUÇÃO}

Os estudos que envolvem a construção de uma Base Nacional Comum surgem com força relevante no final de 2014 e início de 2015, mas sua nomenclatura já foi consolidada desde o ano de 1996 quando foi aprovada a Lei de Diretrizes e Bases da Educação (9394/96). Nesse sentido, busca-se nesse artigo, discutir o significado de um currículo multicultural presente nas Diretrizes Curriculares Nacionais e explicitado na Base Nacional

Comum. Sustenta-se esse estudo nas teorias curriculares críticas.

Essa perspectiva crítica do currículo se diferencia das teorias tradicionais, que têm como pressuposto a neutralidade e cientificidade. $O$ currículo com base nas teorias tradicionais reduz-se numa atividade meramente técnica, o que contribui para a reprodução, pela educação, de desigualdades culturais e sociais. O desafio da perspectiva crítica se consolida ao perceber que no contexto educacional existem as conexões de poder entre o saber e a identidade dos sujeitos o que impulsiona o currículo como uma construção social, histórica e política. Nesse viés rejeita-se, a discussão o caráter prescritivo do currículo apontado pela perspectiva tradicional ou sua redução a uma atividade essencialmente técnica, o que contribui para a reprodução das desigualdades culturais e sociais. A defesa está em perceber a escola como um espaço de construção de uma sociedade mais democrática 
e justa, em que não há neutralidade nas ações ou decisões curriculares que são legitimadas pelas políticas públicas brasileiras. Assim, discute-se aqui o significado de um currículo multicultural presente nas Diretrizes Curriculares Nacionais, pois considera-se, que toda análise relacionada ao currículo está referenciada aos contextos mais amplos que o envolvem.

Nesse contexto, emerge a questão provocadora: Quais os indicativos de um currículo multicultural estão presentes nas Diretrizes Curriculares Nacionais (2013) e que nos impulsionam para uma perspectiva de Base Nacional Comum que vigore a respeito da pluralidade de valores e culturas no âmbito educacional? Assim, esse artigo será dividido em categorias de estudo: Papel dialógico da Perspectiva Crítica de Currículo e Perspectiva de Currículo presente na Base Nacional Comum.

A pesquisa foi desenvolvida em uma única etapa de análise documental das Diretrizes Curriculares Nacionais (BRASIL, 2013) e suas indicações para um currículo multicultural. E, para tanto, à técnica de análise de conteúdo foi utilizada. Essa análise procurou evidenciar a frequência com que palavras ou conjunto de palavras relacionadas ao multiculturalismo apareciam no documento e se privilegiou os aspectos qualitativos dos textos, procurando os temas que davam significação ao documento completo. As palavras pesquisadas nas DCNs inicialmente foram: Currículo Multicultural. Multiculturalidade - Multicultural - Multiculturalismo - Diversidade Cultural Pluralidade Cultural. Após a identificação das palavras relaciona-se as palavras com as modalidade de ensino abordadas e em seguida, o que diziam as frases em que essas palavras apareceram.

\section{PAPEL DIALÓGICO DA PERSPECTIVA CRÍTICA DE CURRÍCULO}

Entender o currículo dessa forma significa, em primeiro lugar, reconhecer seu papel ideológico (APPLE, 2006; MOREIRA, 2007; MOREIRA e CANDAU, 2010), já que na perspectiva curricular crítica, o currículo está fortemente relacionado às estruturas econômicas, sociais e políticas uma vez que nele estão corporificados os resultados de uma seleção de interesses de 


\section{CRIAR EDUCAČ̃̃̃O}

Revista do Programa de Pós-Graduação em Educação - UNESC

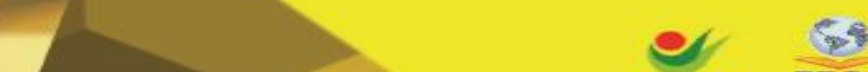 \\ unesc PPG:

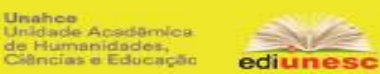

classes e grupos determinados. Assim, funciona como força legitimadora de desigualdades presentes no contexto, e não o resultado de um processo neutro, como defendem as teorias tradicionais.

[...] as formas de conhecimento (tanto aberto quanto oculto) encontradas nas escolas implicam noções de poder e de recursos e controle econômicos. A própria escolha do conhecimento escolar, o ato de designar os ambientes escolares, embora possam não ocorrer conscientemente, são com frequência baseados em pressuposições ideológicas e econômicas que oferecem regras do senso comum para o pensamento e a ação dos educadores (APPLE, 2006, p. 84).

Para Apple (2006), tanto o currículo e quanto a escola são instrumentos poderosos para a "manutenção da hegemonia ideológica" das classes dominantes. Essa hegemonia pode explicar como as condições econômicas controlam a atividade cultural e dominam os valores e as ações vividas, constituindo uma realidade. Isso implica que padrões fundamentais sejam mantidos e que operam como regras naturalizadas. Essa perspectiva direciona o diálogo para um currículo que não é neutro, mas incorpora compromissos econômicos e políticos de modo a produzir e ampliar as desigualdades. A ampliação desse diálogo está em compreender como a valorização das identidades e das diferenças são construídas no contexto educacional. Emerge dessa conjuntura marcada por desigualdades e identidades a defesa de uma educação multicultural. Canen e Moreira (2001, p. 30) apontam a existência de dois propósitos básicos para o processo curricular, pensado à luz do multiculturalismo crítico: "promover o respeito pela diversidade e preparar os alunos para o trabalho coletivo em prol da justiça social". Moreira e Candau também (2007, p. 30) exprimem o desejo de:

[...] intensificar a sensibilidade do(a) docente e do gestor para a pluralidade de valores e universos culturais, para a necessidade de um maior intercâmbio cultural no interior de cada sociedade e entre diferentes sociedades, para a conveniência de resgatar manifestações culturais de determinados grupos cujas identidades se encontram ameaçadas, para a importância da participação de todos no esforço por tornar o mundo menos opressivo e injusto, para a urgência de se reduzirem discriminações e preconceitos. 


\section{CRIAR EDUCAČ̃̃̃O}

Revista do Programa de Pós-Graduação em Educação - UNESC

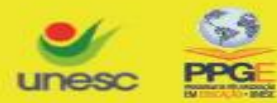

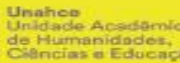

Esses autores direcionam o diálogo para a construção de uma sociedade mais democrática e solidária, que contemplem no currículo, os elementos referentes à promoção dos direitos humanos e a adoção da perspectiva multicultural dentro de uma Base Nacional Comum que crie a possibilidade de dar voz e vez aos diferentes grupos e que o conhecimento seja respaldado por uma discussão ampla sobre os diferentes valores, crenças, modos de vida, que se calaram durante uma centena de anos em nome da igualdade e neutralidade.

Ao evidenciar nesse artigo a articulação entre o multiculturalismo e teoria curricular crítica (MOREIRA; SILVA, 2002), defende-se um posicionamento segundo o qual o currículo não constitui um elemento neutro e vazio de representação, mas se concretiza a partir das dimensões culturais, políticas e ideológicas, marcado por relações assimétricas de poder.

Assim, o currículo aqui discutido é a "peça do sistema cultural mais amplo e, portanto, como campo de conflitos em torno da representação de vozes culturais e da produção de significados" (CANEN; MOREIRA, 2001, p. 31). Isso revela uma natureza contraditória em que o currículo, ao mesmo tempo, em que constitui um instrumento de poder para a "manutenção da hegemonia ideológica" como nos revela Apple (2006), também é campo de conflito e resistência.

O diálogo travado nesse artigo, defende uma Base Nacional Comum que propicie à formação de identidades sensíveis à diferença e comprometidas em desafiar as relações de poder e as ideologias que reproduzem discriminações, desigualdades e preconceitos indo ao encontro dos fundamentos que orientam a nação brasileira e que estão definidos constitucionalmente no artigo $1^{\circ}$ da Constituição Federal:

[...] que trata dos princípios fundamentais da cidadania e da dignidade da pessoa humana, do pluralismo político, dos valores sociais do trabalho e da livre iniciativa. Nessas bases, assentam-se os objetivos nacionais e, por consequência, o projeto educacional brasileiro: construir uma sociedade livre, justa e solidária; garantir o desenvolvimento nacional; erradicar a pobreza e a marginalização e reduzir as desigualdades sociais e regionais; promover o bem de todos sem preconceitos. 


\section{CRIAR EDUCAÇÃO \\ Revista do Programa de Pós-Graduação em Educação - UNESC}

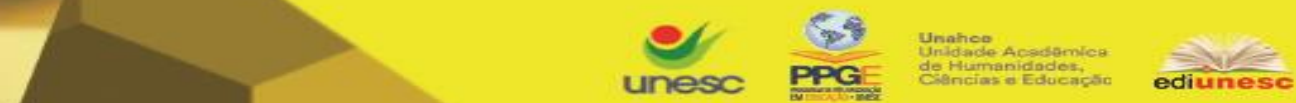

Desse modo a defesa está em perceber que ao evidenciar as relações de interdependência e de poder presentes nas diferentes culturas, a perspectiva multicultural tem o potencial de conduzir a uma profunda transformação do currículo de Base Nacional Comum. E, essa ideia diz respeito a todos, uma vez que ao se educar numa "sociedade multicultural e pluriétnica" (BRASIL, 2013, p. 512) direciona a construção de uma nação democrática.

Muitas ações foram sendo construídas para que a educação estivesse sendo qualificada e que foram compondo a educação nacional no Brasil, servindo como desafio para a expansão da mesma. Moreira (2010) questiona "o conhecimento que se ensina e se aprende na escola" (p.61) e também traz importante discussão sobre o multiculturalismo apresentando algumas frentes que discutem essa temática as quais refere-se:

Atitude a ser desenvolvida em relação à pluralidade cultural; meta a ser alcançada em um determinado espaço social; estratégia política referente ao reconhecimento da pluralidade cultural, corpo técnico de conhecimentos que buscam entender a realidade cultural contemporânea; caráter atual das sociedades (MOREIRA, 2010, p. 176).

É importante lançar algumas discussões a respeito da construção da Base Nacional Comum com relação à compreensão "da realidade cultural contemporânea" (MOREIRA, 2010, p. 176). Nas leituras de Moreira (2010), a multiculturalidade compreende um campo de situações que envolvem refletir sobre qual sociedade tem-se e de que forma esta se constitui. Implica em compreender a educação multicultural para "integrar grupos que contestem valores e práticas dominantes" (2010, p. 177). E, não se pode esquecer que 0 termo "diferença" corrobora para a compreensão do multiculturalismo e o que aponta Moreira (2010, p. 177) que esse termo refere-se "mas à distribuição desigual de pessoas na organização social, decorrente de aspectos que centralmente as distinguem do que a ideia de grupos e indivíduos distintos partilhando aspectos comuns a uma única raça: a humana".

Criar Educação, Criciúma, v. 6, no1, janeiro/junho 2017.- PPGE - UNESC 


\section{PERSPECTIVA DE CURRÍCULO PRESENTE NA BASE NACIONAL COMUM}

No decorrer do ano de 2014 o Ministério da Educação vem enfatizando em seus documentos oficiais a construção de uma Base Nacional Comum. A partir da aprovação do Plano Nacional de Educação (PNE) para a década de 2014-2024 - por meio da Lei 13.005 de 25 de junho de 2014 - o Governo Federal tem exigido o cumprimento das metas 2.2 e 3.3 do referido PNE. O perspectiva de uma Base Nacional Comum não é novidade no Brasil. Em termos legais, essa ideia está presente na Constituição Federal do Brasil (1988), em seu artigo 210 que exprime: "serão fixados conteúdos mínimos para - Ensino Fundamental, de maneira a assegurar formação básica comum e respeito aos valores culturais e artísticos, nacionais e regionais". Além disso, está evidenciada nas Diretrizes e Bases da Educação Nacional Brasileira (LDB 9394/96) no seu artigo 26: "os currículos da Educação Infantil, do Ensino Fundamental e do Ensino Médio devem ter base nacional comum, a ser complementada, em cada sistema de ensino e em cada estabelecimento escolar".

Esses dois documentos oficiais fundamentam a defesa de uma Base Nacional Comum que está também presente nos Parâmetros Curriculares Nacionais (PCN's) de (1997) e nas das Diretrizes Curriculares Nacionais (DCN's) de (1998) e de (2013). Muitas críticas se fez a partir desses documentos, especialmente os alertas propostos pela Anped sobre os Parâmetros Curriculares Nacionais (1996) e sobre a Base Nacional Comum em 2015 que, dentre tantas proposições, destaca a necessidade de que fossem criados espaços para o debate coletivo para essas discussões já que muitas instituições:

Enquanto os PCN's se constituíram como um referencial com um caráter não-obrigatório, as DCN's assumem a obrigatoriedade e, desde então, passaram por reformulações com o objetivo de atender as demandas sociais, culturais e educacionais. As DCN's (2013) são elaboradas com a proposta de 
dar continuidade à sistematização dos princípios contidos na Constituição

Federal e na LDB 9394/96. O foco está centrado em assegurar a formação básica comum nacional;

\begin{abstract}
Entende-se por base nacional comum, na Educação Básica, os conhecimentos, saberes e valores produzidos culturalmente, expressos nas políticas públicas e que são gerados nas instituições produtoras do conhecimento científico e tecnológico; no mundo do trabalho; no desenvolvimento das linguagens; nas atividades desportivas e corporais; na produção artística; nas formas diversas e exercício da cidadania; nos movimentos sociais [...] (BRASIL, 2013, p. 31)
\end{abstract}

Nesse aspecto, a Base Nacional Comum:

[...] denomina "estrutura do documento e de seus fundamentos", uma descaracterização do estudante em sua condição de diferença, bem como da desumanização do trabalho docente em sua condição criativa e desconsideração da complexidade da vida na escola. A conversão do direito a aprender dos estudantes numa lista de objetivos conteudinais a serem aprendidos retira deste direito seu caráter social, democrático e humano. (ANPED, 2015, p. 1)

Como defende-se nesse trabalho, o olhar multiculturalista converge sobre a sala de aula, as diferenças culturais e as relações que se estabelecem no âmbito educacional. Mas, isso não está sendo prioridade na Base Nacional Comum, porque sua lógica é autoritária e vem a contramão do que está presente nas Diretrizes Curriculares Nacionais de 2013 que prega uma perspectiva sistêmica de aprendizagem e respeito pelas diferenças.

Lutamos contra algo que nos assusta, que é a defesa, a partir desta seleção de conhecimentos disciplinares, da ideia de um currículo nacional, desconsiderando a multiplicidade de conhecimentos decorrente da pluralidade de modos de compreender o mundo e de nele intervir, de desejos e intenções, derivada de uma pluralidade também de atores sociais do país, na escola e fora dela. (ANPED, 2015, p. 4)

Sonhos e lutas por escolas onde as conversas complicadas (Currículo) incorporam às práticas em currículos e professores são reconhecidos por seu papel principal de criadores do conhecimento e pensados por Willian Pinnar (2009). Esse autor também contribui para pensar e rever os percursos da 


\section{CRIAR EDUCAČ̃̃̃O}

Revista do Programa de Pós-Graduação em Educação - UNESC

\section{Unesc PPGE}

escola, compreender as relações que se estabelecem em seus contextos. Um olhar multiculturalista que propõe o encontro e a compreensão das relações. Mas, para esse autor, há o cuidado com o "multiculturalismo malicioso" (2009). O olhar desse autor para o multiculturalismo passa pelos educadores. Salienta que "como educadores, nosso papel é o de participar na conversa complicada que é o currículo" (2009, p. 162).

A Base Nacional Comum no momento histórico que está sendo construída, nessa "conversa complicada" (PINAR, 2009) de repensar as teorias e práticas pedagógicas no contexto da escola acrescenta rupturas que ao longo dos anos foi intensificando, como a abertura do debate em torno das especificidades dos conteúdos e seu conhecimento nos mais diversos níveis de ensino.

Esse entendimento vai permitir que o pensamento crítico e a concepção teórica estejam imbricados nos contextos educativos e a perspectiva multicultural. Conforme a BNC (2015), "a identificação e a caracterização da área das Ciências Humanas ocorrem a partir da compreensão das especificidades dos pensamentos filosóficos, históricos, geográficos, sociológicos e antropológicos" e acontece em toda a Educação Básica. Importante ainda salientar que os componentes básicos que fazem parte dessa área na educação escolar são: "História e Geografia, desde o Ensino Fundamental até o Ensino Médio, e Sociologia e Filosofia, exclusivamente no Ensino Médio" integrados ainda o Ensino Religioso "dada sua proximidade de estudos com a área de Ciências Humanas, é a ela integrado na Base Nacional Comum Curricular (BNC), realçando seu caráter histórico e filosófico" (BNC, 2015 p. 257).

Correspondendo à base nacional comum, ao longo do processo básico de escolarização, a criança, o adolescente, o jovem e o adulto devem ter oportunidade de desenvolver, no mínimo, habilidades segundo as especificidades de cada etapa do desenvolvimento humano, privilegiando-se os aspectos intelectuais, afetivos, sociais e políticos que se desenvolvem de forma entrelaçada, na unidade do processo didático. (BRASIL, 2013, p. 33) 


\section{CRIAR EDUCAČ̃̃̃O}

Revista do Programa de Pós-Graduação em Educação - UNESC

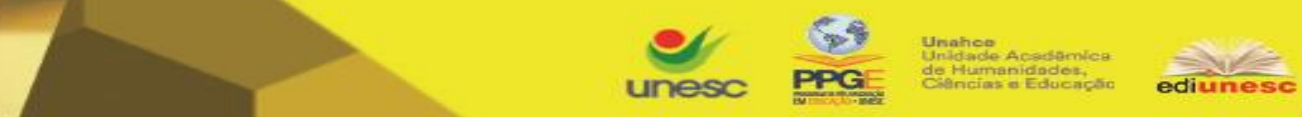

Por isso que Moreira e Candau (2008) destacam suas inquietações relativas aos conhecimentos que deveriam compor os currículos escolares e a relevância em se discutir as relações entre currículo e cultura (s) evidenciando a questão da pluralidade/diversidade cultural como dimensão central do currículo. Nesse sentido, "elaborar currículos culturalmente orientados demanda uma nova postura, por parte da comunidade escolar, de abertura às distintas manifestações culturais". (STOER; CORTESÃO, 1999 apud MOREIRA \& CANDAU, 2008, p.31). Então um currículo de Base Nacional Comum defende o multiculturalismo como nos propõe Moreira\&Candau (2008, p. 20):

[...] é inegável a pluralidade cultural do mundo em que vivemos e que se manifesta, de forma impetuosa, em todos os espaços sociais, inclusive nas escolas e nas salas de aula. Essa pluralidade frequentemente acarreta confrontos e conflitos, tornando cada vez mais agudos os desafios a serem enfrentados pelos profissionais da educação. No entanto, essa mesma pluralidade pode propiciar o enriquecimento e a renovação das possibilidades de atuação pedagógica.

Entendemos que as perspectiva de currículo presente na Base Nacional Comum da forma como foi organizada mesmo tendo seus princípios baseados nos Componentes Curriculares Nacionais, sinaliza uma educação voltada apenas aos objetivos de aprendizagem, o que caracteriza "o distanciamento entre a produção teórica e a realidade vivida no cotidiano das escolas" (MOREIRA, 2010, 14

\section{ANÁLISE E TRATAMENTO DE DADOS}

As palavras pesquisadas nas DCN's inicialmente foram: Currículo Multicultural - Multiculturalidade - Multicultural - Multiculturalismo - Diversidade Cultural - Pluralidade Cultural. Após a identificação das palavras buscou-se em seguida, os significados dessas palavras nos excertos do texto nas quais as palavras aparecem.

Criar Educação, Criciúma, v. 6, nำ1, janeiro/junho 2017.- PPGE - UNESC 


\section{Unesc PPGE}

Nessa esteira, a partir das nossas leituras e análises das DCN's (2013), seleciona-se excertos que tratam dos temas acima destacados. A seguir mostra a quantidade dos temas que se relacionou com o currículo multicultural e que aparecem nas diretrizes curriculares: Currículo Multicultural (00); Multiculturalidade (03); Multicultural (09); Multiculturalismo (02); Diversidade Cultural (29); e, Pluralidade Cultural (07).Ao analisarmos as Diretrizes Curriculares Nacionais Gerais para a Educação Básica (2013), pode-se perceber muitos dos significados que estão relacionados a uma base curricular nacional pautada na Multiculturalidade e na pluralidade ou diversidade cultural.

Não obstante, essa análise revela que muitos aspectos presentes nas Diretrizes Gerais são postos como condições para a elaboração de uma Base Nacional Comum. Para a realização desse estudo, apresentaremos alguns excertos que compõe as DCNs. Todavia, ressalta-se que este foi um modo particular de perceber as DCN's, o qual, "visto com outras lentes", poderá ter outros sentidos.

O tema multiculturalidade nas DCN's (2013) estão muito presente nas diretrizes da Educação Ambiental, da Educação de Campo por serem uma demanda da educação novas, enfatizando necessidades básicas da "convivência com os meios de comunicação e a cultura letrada".(BRASIL, 2013, p.268) E, por ter como foco as práticas comprometidas com a igualdade, solidariedade, e sustentabilidade:

[...] com base em práticas comprometidas com a construção de sociedades justas e sustentáveis, fundadas nos valores da liberdade, igualdade, solidariedade, democracia, justiça social, responsabilidade, sustentabilidade e educação como direito de todos e todas, são princípios da Educação Ambiental:[...] VI - respeito à pluralidade e à diversidade, seja individual, seja coletiva, étnica, racial, social e cultural, disseminando os direitos de existência e permanência e o valor da multiculturalidade e plurietnicidade do país e do desenvolvimento da cidadania planetária. (BRASIL, 2013, p.550)

Nessa mesma perspectiva, busca-se o conceito de Multicultural relacionado as Diretrizes e encontra-se um relacionamento com o Ensino fundamental, Educação Ambiental, Educação de Campo, Educação 


\title{
CRIAR EDUCAČ̃̃̃O
}

Revista do Programa de Pós-Graduação em Educação - UNESC

\section{Unesc PPGE}

Quilombola e Educação para as Relacões Étnico-raciais em que se propõe a compreensão das identidades e diferenças "construídas determinando a valorização de uns e o desprestígio de outros. É, nesse contexto, que emerge a defesa de uma educação multicultural”. (BRASIL, 2013, p. 105). Nesse cenário, o Multiculturalismo e as diferenças tornaram-se o centro das discussões.

Muitas delas tendem a ser incluídas nas propostas curriculares pela adoção da perspectiva multicultural. Entende-se, que os conhecimentos comuns do currículo criam a possibilidade de dar voz a diferentes grupos como os negros, indígenas, mulheres, crianças e adolescentes, homossexuais, pessoas com deficiência. (BRASIL, 2013, p. 115)

Para Moreira (2002) o Multiculturalismo tem sido empregado para indicar o caráter plural das sociedades de modo a incrementar o esforço de examinar as culturas e questioná-las. Desse modo o autor, propõe um diálogo entre as diferentes culturas de forma sob o olhar do Multiculturalismo, "para que melhor se compreenda os processos de construção das diferenças e de promoção de diálogo". (p.20). O que nos revela que a Base Nacional Comum com respaldo do multiculturalismo defende a diferença que é produto da História, da ideologia e das relações de poder.

\begin{abstract}
A perspectiva multicultural no currículo leva, ainda, ao reconhecimento da riqueza das produções culturais e à valorização das realizações de indivíduos e grupos sociais e possibilita a construção de uma autoimagem positiva a muitos alunos que vêm se defrontando constantemente com as condições de fracasso escolar, agravadas pela discriminação manifesta ou escamoteada no interior da escola. Além de evidenciar as relações de interdependência e de poder na sociedade e entre as sociedades e culturas, a perspectiva multicultural tem 0 potencial de conduzir a uma profunda transformação do currículo comum. (BRASIL, 2013, p. 115).
\end{abstract}

Essas discussões estão presentes nas Diretrizes da Educação de Campo, da Eduacação Quilombola e Educação das Relações Étnico-raciais o que revela que é "possível aprender um novo tipo de relacionamento entre saberes e, portanto, entre pessoas e grupos sociais. Poderá emergir daí um relacionamento mais igualitário e mais justo que nos faça apreender o mundo 


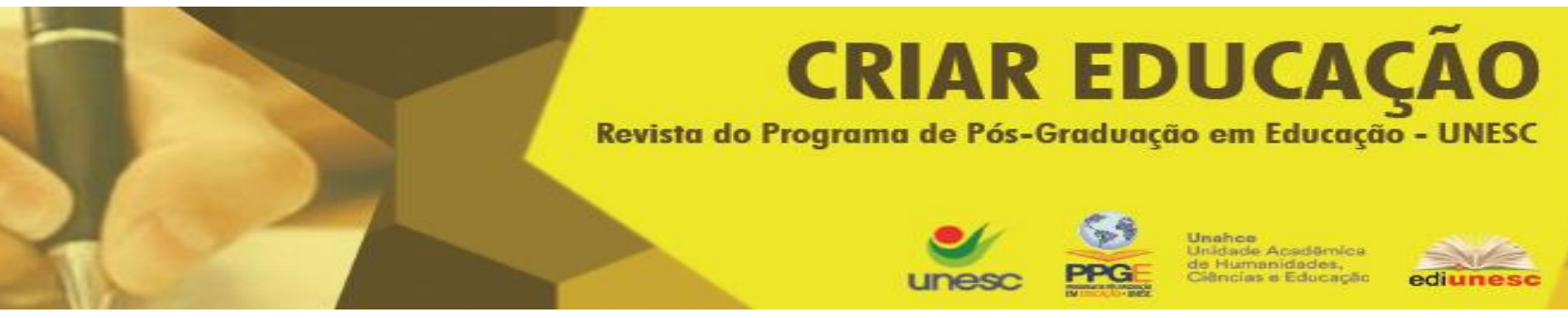

de forma edificante, emancipatória e multicultural." (BRASIL, 2013, p. 467). O conceito de multiculturalismo presente nas Diretrizes gerais das DCN's (2013), revela em sua constituição as bases teóricas, como o racismo, as discriminações, a intolerância, o preconceito, o estereótipo, a raça, a etnia, a cultura, a classe social, a diversidade cultural e a diferença.

\begin{abstract}
A escola de qualidade social adota como centralidade o diálogo, a colaboração, os sujeitos e as aprendizagens, o que pressupõe, sem dúvida, atendimento a requisitos tais como: [...] II - consideração sobre a inclusão, a valorização das diferenças e o atendimento à pluralidade e à diversidade cultural, resgatando e respeitando os direitos humanos, individuais e coletivos e as várias manifestações de cada comunidade (p. 22)
\end{abstract}

Essa perspectiva está presente em todas as modalidades. A partir destes fundamentos, aponta-se a questão da pluralidade/diversidade cultural como dimensão central das DCN's e consequentemente da Base Nacional Comum.

[...] legitimam-se saberes socialmente reconhecidos e estigmatizamse saberes populares. Nessa hierarquia, silenciam-se as vozes de muitos indivíduos e grupos sociais e classificam-se seus saberes como indignos de entrarem na sala de aula e de serem ensinados e aprendidos. Nessa hierarquia, reforçam-se relações de poder favoráveis à manutenção das desigualdades e das diferenças que caracterizam nossa estrutura social. (MOREIRA \& CANDAU, 2008, p. 25).

Nas DCN's considera essencial que no currículo seja contemplado temas como inclusão, valorização das diferenças e atendimento à pluralidade $\mathrm{e}$ "diversidade cultural, resgatando e respeitando as várias manifestações de cada comunidade". (p. 65). Há indicação no Art. 16 que os componentes curriculares se articulem com conteúdo da base nacional comum e da parte diversificada temas como: "saúde, sexualidade e gênero, vida familiar e social, assim como os direitos das crianças e adolescentes, de acordo com o Estatuto da Criança e do Adolescente [...] preservação do meio ambiente, educação para o consumo, educação fiscal, trabalho, ciência e tecnologia, e diversidade cultural (BRASIL, 2013,p. 134) 


\section{CRIAR EDUCAÇÃO \\ Revista do Programa de Pós-Graduação em Educação - UNESC \\ unesc \\ PPG

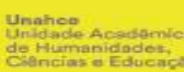 \\ ediunesc}

$\rightarrow \quad 0 \%$ है

A proposta educativa da unidade escolar, o papel socioeducativo, artístico, cultural, ambiental,as questões de gênero, etnia e diversidade cultural que compõem as ações educativas, a organização e a gestão curricular são componentes integrantes do projeto político-pedagógico, devendo ser previstas as prioridades institucionais que a identificam, definindo o conjunto das ações educativas próprias das etapas da Educação Básica assumida, de acordo com as especificidades que lhes correspondam, preservando a sua articulação sistêmica. (BRASIL, 2013, p. 177)

Nas DCNs (2013) a Pluralidade Cultural também está presente nas Diretrizes Gerais que servem de base para todas as modalidades de ensino em que enfatiza "à relevância de um projeto político-pedagógico concebido e assumido coletivamente pela comunidade educacional, respeitadas as múltiplas diversidades e a pluralidade cultural;" (BRASIL, 2013, p. 23 e 65). Isso nos impulsiona a "incorporação à comunhão nacional, reconhece a pluralidade cultural e o Estado brasileiro como pluriétnico". (BRASIL, 2O13, p. 378 ). Nas DCN (2013) enfatizam que "a construção de relações interétnicas orientadas para a manutenção da pluralidade cultural, pelo reconhecimento de diferentes concepções pedagógicas [...] como sujeitos de direitos". (BRASIL, 2013, p. 405).

\section{CONSIDERAÇÕES FINAIS}

A Base Nacional Comum, já anunciada e legalizada na década de 90 , apresenta nesse momento de sua construção alguns elementos necessários que emergem necessidades reais de discussão. Os indicativos de um currículo multicultural presentes nas Diretrizes Curriculares Nacionais (2013) e que nos impulsionam para uma perspectiva de Base Nacional Comum precisa conceber o contexto da sala de aula, as implicações em seu entorno e amplo debate de conhecimentos que compreendam e atue sobre a "realidade Cultural Contemporânea" (MOREIRA, 2010 p. 176) para que vigore o respeito e a pluralidade de valores e culturas no âmbito educacional.

Sabe-se das mobilizações realizadas pelas escolas brasileiras a respeito do movimento da BNC, mas entende-se que algumas lacunas não foram 
identificadas com o tempo necessário para essas mobilizações, a compreensão da geração do material que deveriam imergir das comunidades escolares e as condições sociais de estabelecimento de um Currículo que atenda uma perspectiva multicultural.

Quais propostas vêm sendo construídas no movimento da BNC para enfrentar os desafios decorrentes dessa realidade cultural contemporânea? Portanto, há de se instalar no âmbito da escola um entrelaçamento de discussões que imperem para uma Base Nacional Comum que extrapole os objetivos de aprendizagem dos documentos e permeiem por uma "experiência curricular multiculturalmente orientada" (MOREIRA, 2010 p. 186) a fim de rever as contradições e resistências no processo formativo tanto dos professores quanto dos alunos e da comunidade em geral.

\section{REFERÊNCIAS}

APPLE, Michael. Ideologia e Currículo. 3ㅗㄹ ed. Porto Alegre. Artmed, 2006.

BRASIL, Educação brasileira: indicadores e desafios: documentos de consulta / Organizado pelo Fórum Nacional de Educação. -- Brasília: Ministério da Educação, Secretaria Executiva, Secretaria Executiva Adjunta, 2013. 95 p.

BRASIL. Base Nacional Comum Curricular - BNC - Disponível em BRASIL. Diretrizes Curriculares Nacionais Gerais da Educação Básica / Ministério da Educação. Secretaria de Educação Básica. Diretoria de Currículos e Educação Integral. Brasília: MEC, SEB, DICEI, 2013. http://basenacionalcomum.mec.gov.br/\#/site/linha-do-tempo. 2015

MOREIRA Antônio Flávio Barbosa. Indagações sobre currículo: currículo, conhecimento e cultura . Brasília : Ministério da Educação, Secretaria de Educação Básica, 2007. 
MOREIRA, Antonio Flávio Barbosa. A recente produção científica sobre currículo e Multiculturalismo no Brasil. (1995-2000): Avanços, desafios e tensões. Revista Brasileira de Educação, oํ 18, 2001.

MOREIRA, Antonio Flávio Barbosa \& CANDAU, Vera Maria. Educação escolar e cultura (s): construindo caminhos. Revista Brasileira de Educação, no 23,2003

PINAR, Willian. Multiculturalismo malicioso. Currículo sem Fronteiras, v.9, n.2, pp.149-168, Jul/Dez 2009

Criar Educação, Criciúma, v. 6, nำ1, janeiro/junho 2017.- PPGE - UNESC 